DOI: https://doi.org/10.31392/NZ-npu-144.2019.28

УДК 378.811

Чень Ченьлин, Сюй Менглин

\title{
АДАПТАЦИЯ ИНОСТРАННЫХ ЭКСПЕРТОВ В КНР
}

В статье анализируются особенности адаптации иностранных экспертов, постоянно работающих в провинции Чжещзян; раскрываются основные направления адаптаџии, такие как межллчностная, психологическая, культурная, бытовая. Освещзаются факторы, влияюшие на межкультурную адаптаџию экспертов из разных стран и предлагаются мероприятия, которые могут содействовать их адаптации кместной культуре.

Ключевые слова: межкультурная адаптаџия, иностранные эксперты, провинция Чжсэизян.

(стаття подана мовою орихіналу)

В условиях интернационализации высшего образования в КНP привлечение широкого круга иностранных учёных и специалистов с широкими профессиональными знаниями постепенно становится важным фактором развития китайских университетов. В последние годы во всех регионах страны активно реализуется “План тысячи талантливых людей”. Правительство Китая разработало комплекс мероприятий по привлечению в Китай талантливых иностранных специалистов для проведения научных исследований совместно с китайскими компаниями и университетами.

Однако, способствуя интернационализации китайской системы образования, активизации научных исследований, внедрению инноваций, иностранные эксперты сталкиваются с рядом проблем, вызванных межкультурными различиями. Данное исследование посвящено вопросам адаптации иностранных экспертов в провинции Чжэцзян. Развёрнутые интервью с иностранными экспертами, работающими в университетах провинции Чжэцзян, помогают детально проанализировать проблемы, которые существуют в процессе культурной адаптации иностранных экспертов, выявить способы адаптации, принимаемые иностранными экспертами, а также, условиях, влияющие на этот процесс.

Целью данного исследования является изучение социокультурной адаптации иностранных специалистов, анализ и обобщение различных факторов, влияющих на адаптацию; изучение способов адаптации и условий, влияющих на эффрективную работу и качественную коммуникацию с академической и культурной средой Китая. Такое исследование будет иметь большое значение для продвижения международных научных обменов.

Обобщающие теоретические работы о процессе культурной адаптации в чужой культурной среде публикуются уже длительное время. Среди научно значимых исследований по данной тематике следует упомянуть работу Р. Редфилда, Р.Линтона и М. Херсковица, изданную в 1936 г. Они определили культурную адаптацию, как “феномен непрерывного и прямого 
культурного контакта между двумя группами, состоящими из людей разных культур, который приводит к изменениям в первоначальных культурных моделях одной или обеих сторон" [1].

В наше время Д. Вудберри (2006) считает, что культурная адаптация это "культурные и психологические изменения, сопровождаемые культурными контактами" [2]. Однако исследователи придерживаются разных мнений о компонентах культурной адаптации.

Так, М. Менденхал и Г. Одду (1985) [3] отстаивают точку зрения, что культурная адаптация включает три компонента: эмоции, поведение и познание. С. Уорд и А. Кеннеди (1992) [4] разделяют культурную адаптацию на две составляющие: психологическую и социокультурную адаптацию. Сунь Лечен и др. (2009) [5] считают, что культурная адаптация в определенной степени является “тотальной адаптацией”. Она включает три компонента: социальная адаптация, психологическая адаптация и культурная адаптация.

Под социальной адаптацией понимается способность мигрантов корректировать свое поведение в соответствии с потребностями повседневной социальной жизни в новой социальной среде. Психологическая адаптация относится к способности приспосабливаться и поддерживать позитивный настрой в новой социальной среде. Культурная адаптация подразумевает понимание или принятие идей, ценностей и поведения местного населения.

Кроме того, с помощью различных эмпирических исследований исследователи обнаружили, что существуют различные фракторы, влияющие на культурную адаптацию, такие как различия между материнской культурой и основной культурой, т.е. культурная дистанция. Демографические переменные включают нацеленность иностранцев на изучение иностранного языка, а также пол, возраст, уровень образования, межкультурный опыт, религиозную культуру и так далее.

Чэнь Хуэй и Че Хуншен (2003) [6] суммировали соответствующие исследования в Китае и пришли к выводу, что фракторы, влияющие на межкультурную адаптацию, можно условно разделить на внутренние и внешние. Внешние фракторы включают изменение жизни, социальную поддержку, продолжительность пребывания, дискриминацию и предрассудки, а внутренние фракторы включают когнитивную оценку, способ реагирования, личность и культурные знания и навыки.

В Китае с каждым годом увеличивается количество теоретических и эмпирических исследований по проблеме общей социальной и культурной адаптации иностранцев. Однако, общее число исследований по этой тематике невелико, а исследования по культурной адаптивности иностранных экспертов ещё меньше.

По сравнению с иностранными преподавателями эта группа имеет свои особенности. Например, эксперты в университетах должны выполнять не только учебные, но и научно-исследовательские задачи .

В ситуации, когда иностранным специалистам необходимо заниматься 
преподавательской работой и решать трудные научно-исследовательские задачи рабочие нагрузки на них многократно возрастают. Здесь они сталкиваются с собственными проблемами адаптации. Поэтому по сравнению с обычными иностранными преподавателями, культурная адаптивность этих иностранных специалистов предстаёт в особой, специфической фрорме.

\section{2. Проект исследования.}

\section{1. Предмет исследования.}

Объектом исследования являются пять иностранных экспертов из Университета Хучжоу, которые представляют Россию, Украину и Беларусь. Их учебная нагрузка состоит в преподавании различных учебных предметов в курсе русского языка в институте иностранных языков, а в научноисследовательские задачи входит написание статей в университетские научные издания (сборники научных статей, журналы) и работа в рамках научно-исследовательских проектов.

Таблица 1

Персональная информация об иностранных экспертах

\begin{tabular}{|l|c|c|c|c|c|l|}
\hline \multicolumn{1}{|c|}{ ФИО } & Пол & Возраст & $\begin{array}{c}\text { Семейное } \\
\text { положение }\end{array}$ & $\begin{array}{c}\text { Время жсизи в } \\
\text { Китае }\end{array}$ & $\begin{array}{c}\text { Когда-нибудь жили } \\
\text { за границей? }\end{array}$ & Нагрузка \\
\hline \hline $\begin{array}{l}\text { Иностранный } \\
\text { эксперт В }\end{array}$ & $\mathrm{M}$ & $\begin{array}{c}50-60 \\
\text { лет }\end{array}$ & Женат & 3 года & Да & Исследование \\
\hline $\begin{array}{l}\text { Иностранный } \\
\text { эксперт Л }\end{array}$ & Ж & $50-60$ лет & Замуж & 3 года & Да & $\begin{array}{l}\text { Обучение + } \\
\text { исследование }\end{array}$ \\
\hline $\begin{array}{l}\text { Иностранный } \\
\text { эксперт И }\end{array}$ & Ж & $40-50$ лет & Замуж & 1 год & $\begin{array}{l}\text { Обучение }+ \\
\text { исследование }\end{array}$ \\
\hline $\begin{array}{l}\text { Иностранный } \\
\text { экперт С }\end{array}$ & Ж & $40-50$ лет & Замуж & 1 год & Да & $\begin{array}{l}\text { Обучение }+ \\
\text { исследование }\end{array}$ \\
\hline $\begin{array}{l}\text { Иностранный } \\
\text { эксперт Р }\end{array}$ & $\mathrm{M}$ & $30-40$ лет & Холостой & 2 года & Да & Обучение \\
\hline
\end{tabular}

\section{2. Методы исследования.}

Это исследование использует смешанный метод, который сочетает в себе опрос и полуструктурированные интервью.

1) Анкетный опрос. Анкета основана на шкале адаптации к иммиграции. Согласно предыдущему экспериментальному исследованию, авторы добавили, удалили или изменили элементы, относящиеся к шкале адаптации иммиграции, чтобы сделать её более отвечающей специфике исследуемой группы. Целью вопросника является изучение культурной адаптивности иностранных экспертов и выражение такой адаптивности в количественных показателях.

2) Модифицированная шкала адаптации иммиграции содержит четыре подшкалы, которые измеряют степень удовлетворенности своим положением в Китае, отношение к Китаю, ностальгию по родине и физические симптомы. Шкала включает следующие оценки: 4 балла - полностью согласен с этой точкой зрения, 3 балла - в основном согласен с этой точкой зрения, 2 балла в основном не согласен с этой точкой зрения, 1 балл - полностью не согласен с этой точкой зрения. Каждый вопрос предполагает, что ответы респондентов 
на него отражают степень их согласия или не согласия с этим мнением.

3) Полуструктурированное интервью. После сортировки и анализа данных, собранных в опроснике, авторы организуют полуструктурированные последующие интервью. Информация, которая не может быть включена в опросник, дополнительно исследуется с целью сбора данных, необходимых для более полного изучения и разработки дополнительных вопросов для нового опроса.

\section{3. Результаты исследований.}

Собранные данные были проанализированы, а результаты были разделены на четыре аспекта: адаптация к жизни в Китае, адаптация к личности, адаптация к работе и психологическая адаптация.

\section{1. Адаптация к жизни.}

В целом, пять иностранных экспертов довольны жизнью и работой в Китае и демонстрируют базовое состояние адаптации. Среди 25 вопросов респонденты выбрали три ответа с высокой средней ценностью: "Чувствую себя в безопасности, живя в Китае" - в среднем 4 балла; "Мне интересны местные обычаи" (4 балла) и "Извлекаю большую пользу, работая в Китае" (4 балла).

Также было зафиксировано положительное впечатление от иностранных экспертов о провинции Чжэцзян. Например, иностранный эксперт М. чувствовала, что провинция Чжэцзян в целом и город Хучжоу, в частности, безопаснее, чем её родной город.

Некоторые зарубежные эксперты считают, что город Хучжоу, как город третьего уровня, является подходящим местом для жизни потому, что здесь нет шума, скопления машин и загрязнённой атмосферы, свойственной городам первого и второго уровней. Большинство иностранных экспертов считают, что в провинции Чжэцзян и городе Хучжоу развит общественный транспорт и инфраструктура удобна. "Я чувствую себя здесь очень популярным. Мне комфортно", - сказал иностранный эксперт Р., оценивая свою жизненную адаптацию.

\section{2. Межличностная адаптация.}

Большинство иностранных экспертов говорят, что в повседневном общении с китайцами нет больших проблем. Китайцы скромные, отзывчивые и дружелюбные; с интересом относятся к иностранцам, поэтому с ними легко знакомиться. У всех опрошенных иностранных экспертов появились в Китае близкие друзья. У иностранного эксперта С. есть друзья в Китае и она встречается с ними почти каждую неделю. Иностранные эксперты также упомянули некоторые аспекты, которые заставляли их чувствовать себя некомфортно в общественных местах в Китае. Чаще всего иностранные эксперты говорили о своём ощущении, что "местные жители часто смотрят на меня" (4 балла). Однако в интервью они указывали, что, хотя им это было неприятно, они не чувствовали в этом угрозы или отвращения. Они понимали, что такое пристальное внимание к ним было связано с китайским любопытством к людям европейской внешности. Иностранный эксперт М. 
также упомянула о некоторых бытовых недоразумениях в Китае, например, о том, что иногда продавцы, которые видят в ней иностранку, будут намеренно завышать цену.

Что касается межличностного общения, с иностранными экспертами наиболее часто контактируют их китайские студенты и коллеги. Иностранный эксперт И. сказала, что иногда, когда китайцы обнаруживают проблему, они не будут указывать на неё непосредственно, а сделают это косвенно, с помощью намёков. Люди европейской культуры привыкли к более прямолинейному описанию проблемы и своего отношения к ней, что иногда приводит к трениям в общении. Иностранные эксперты пришли к выводу, что, общаясь с китайцами, следует обращать внимание на этот момент и избегать ненужных недоразумений в общении.

\section{3. Рабочая адаптация.}

Нагрузка. Хотя иностранные эксперты придерживаются разных мнений, они в целом согласны с текущей рабочей нагрузкой. Поскольку в обязанности иностранного эксперта В. не входит преподавание, он делает вывод, что его работа в Китае похожа на его работу в России. Иностранному эксперту И. нравится работать со студентами, она считает, что нагрузка могла бы быть большей.

Обучение. Некоторые иностранные эксперты считают, что уровень отдельных китайских студентов нуждается в повышении. Китайские студенты, как правило, учатся пассивно и без должного прилежания, что отличается от активного обучения, к которому они привыкли. Поэтому некоторые иностранные эксперты были разочарованы этим фактом в начале своей преподавательской деятельности в Китае.

\section{4. Психологическая адаптация.}

Результаты опроса показывают, что иностранные эксперты в Китае попрежнему скучают по людям и вещам, которые они оставили на своей родине. Средний балл в ответах по пункту "Я скучаю по своему родному городу" составляет 3 балла, средний балл по пункту "Я скучаю по медиа своего родного города" - 2.6, а средний балл по пункту “я хочу есть дома” - 2.6. Однако тоска по родине не препятствует их успешной адаптации к жизни в Китае. Например, они не согласны с утверждением, что "моими настоящими друзьями могут быть только мои соотечественники" (средний балл ответов - 1.8).

В целом иностранные эксперты, которые участвовали в исследовании, полностью адаптировались к жизни в китайской культурной и бытовой среде. Отдельные китайские бытовые привычки, которые вызывают непонимание иностранцев, не повлияли на эту адаптацию.

Среди таких привычек иностранный эксперт С. упомянула громкую речь в общественных местах и излишнее любопытство. При этом она понимает, что некоторые люди живут так всю свою жизнь и эти привычки являются частью их жизни. Иностранный эксперт В. также придерживается мнения, что, находясь в Китае, следует не только уважать культуру, традиции и обычаи страны пребывания, но и терпимо относится к местным бытовым привычкам, 
даже если они не нравятся.

Иностранные эксперты считают, что качество жизни иностранцев в Китае сильно зависит от качества общения с китайским населением, с коллегами, а это, в свою очередь, зависит от умения адаптироваться ко всем аспектам местной общественной среды.

\section{4. Факторы, влияющие на межкультурную адаптацию зарубежных экспертов.}

Существует множество фракторов, влияющих на межкультурную адаптацию иностранных экспертов. Посредством этого исследования авторы пришли к выводу, что внешние фракторы, которые могут повлиять на межкультурную адаптацию иностранных экспертов, включают культурные различия, время пребывания, религиозные факторы и социальную поддержку. Внутренние фракторы включают языковые способности, опыт межкультурного общения и навыки межкультурной адаптации самих иностранных экспертов.

\section{1. Культурные различия.}

Люди, которые формировались в иной культуре, попадая в Китай, неизбежно сталкиваются с большими различиями в обычаях, правилах и стилях поведения. Например, китайская культура общения в большинстве случаев не предполагает раскрытия всего контекста проблем, просьб, желаний, намерений и настроений. Люди европейской культуры стремятся в процессе общения более открыто и явно обозначать свои проблемы, настроения, желания или интересы, что зачастую вызывает в Китае непонимание. Данное несовпадение может вызывать в общении представителей разных культур известные трения.

\section{2. Время проживания.}

Иностранные эксперты М. и В., которые живут в Китае достаточно долго, лучше адаптировались к китайскому образу жизни, чем другие иностранные эксперты. Некоторым из них может потребоваться пройти более длительный период адаптации, чтобы выработать удобный для себя ритм жизни, работы и общения. Исследование показало, что большинство экспертов провели в Китае сравнительно мало времени, чтобы можно было ожидать полной адаптации в китайскую культурную среду.

Например, иностранный эксперт И. на момент опроса находилась в Китае в провинции Чжэцзян только два месяца, но при этом не испытавала неудобств от работы и жизни в Китае. К тому же она встретила в Университете экспертов, которых она знала по научным контактам в Украине, что также помогло ей адаптироваться.

\section{3. Языковые способности.}

Среди опрошенных экспертов иностранный эксперт М. продвинулась в изучении китайского языка дальше остальных. Тем не менее мы полагаем, что языковая компетенция и адаптивность не являются абсолютно взаимосвязанными. Поэтому недостаточный уровень знания китайского языка не означает низкой адаптированности иностранного специалиста.

Например, иностранный эксперт С. с хорошей адаптивностью владеет 
очень низким уровнем китайского языка. Однако все иностранные эксперты считают, что знание китайского языка влияет в лучшую сторону на повседневную жизнь, работу и межличностное общение. Даже иностранный эксперт М. (прохождение HSK-3) и иностранный эксперт Р. (свободно говорит по-китайский), которые хорошо владеют китайским языком, считают себя "недостаточно адаптированными" к жизни в Китае.

\section{4. Межкультурный опыт.}

Bce иностранные эксперты имеют достаточно большой опыт межкультурного общения. Прошлый опыт работы или учебы за границей помог им освоить больше стратегий культурной адаптации, таких как быстрое понимание местных правил поведения, быстрое понимание местного стиля работы и постоянная саморегуляция.[7]

\section{5. Социальная поддержка.}

Почти все иностранные эксперты отметили, что социальная поддержка является важным фактором. Важную роль играет помощь при знакомстве с китайской культурой, а также в решении проблем социальной и бытовой адаптации, предоставляемая китайскими коллегами.

Некоторые иностранные эксперты отмечали, что, поскольку они плохо понимали китайский язык, им было неудобно каждый раз вводить планы обучения и экзаменационные отметки оценки в университескую систему, что доставляло определённое неудобство.

\section{6. Способность иностранных экспертов к межкультурной адаптации.}

Обобщая данные интервью, авторы пршли к выводу, что способность иностранных экспертов адаптироваться включает три аспекта: культурную эмпатию, активную адаптивность и стратегическую гибкость.

Культурная эмпатия относится к способности людей понимать чувства, взгляды и поведение людей, принадлежащих к разным культурным группам, и понимать различия разных культур. Культурная эмпатия влияет на понимание и восприятие иностранными экспертами новой культуры, а также на скорость её освоения [7]. Украина, Россия и Беларусь, как страны бывшего Советского Союза, сами являются мультикультурными обществами, что облегчает культурную адаптацию иностранных экспертов в китайской социокультурной среде.

У нескольких иностранных экспертов, которые хорошо адаптированы, есть общая черта: они открыты к восприятию нового культурного опыта и не уклоняются от приспособления к новым культурным вызовам.

Первое время пребывания в Китае иностранные эксперты сравнивают Китай со своей страной, отмечая существенные различия. Это вызывает у некоторых опасения о неспособности адаптироваться к иной культурной и бытовой среде. Например, в интервью иностранный эксперт И. упомянула свою коллегу, которая жила в Китае только неделю и вернулась домой потому, что не смогла приспособиться к своей работе.

Открытые и активные иностранные эксперты получают больше возможностей для адаптации к новой культуре, которые предоставляются их 
китайскими коллегами и друзьями .

Под стратегической гибкостью понимается гибкость в принятии поведения, соответствующего культуре. Иностранным экспертам иногда необходимо внести соответствующие поведенческие корректировки, чтобы лучше интегрироваться и адаптироваться [7]. Те, кто применяет соответствующие методы решения проблем в соответствии с конкретной культурной средой, быстро находят общий язык с местными жителями, решают жизненные проблемы, успешнее работают, а также испытывают меньшее культурное отчуждение.

Например, в интервью иностранный эксперт М. отметила, что она обнаружила большее предпочтение китайских студентов к пассивному обучению. Поэтому она изменила свою первоначальную стратегию обучения и проводила больше времени в классе, чтобы поощрить студентов к большим усилиям в учёбе.

\section{5. Предложения.}

\section{1. Подготовить понимание Китая.}

Прежде, чем принять решение о работе в университетах КНР, иностранным экспертам целесообразно получить полное представление о стиле управления, качестве работы персонала и административной системе в Китае.

С одной стороны, слухи о "китайском опыте" могут ввести в заблуждение иностранных экспертов, что вызовет определённые иллюзии, которые затем отрицательно повлияют на последующий процесс адаптации.

С другой стороны, личный опыт освоения организационной культуры китайских университетов поможет иностранным специалистам давать квалифицированные советы их руководству по подбору более подходящих иностранных работников.

\section{2. Открытость и принятие, обратная связь и общение.}

В начале своего пребывания в Китае иностранные эксперты неизбежно столкнутся со многими правилами поведения и культурными привычками, отличными от тех, к которым они привыкли у себя на родине. В этом случае иностранным экспертам уместно рекомендовать терпимо и с пониманием относиться к поведению китайцев и к явлениям, которые они не могут понять в новой среде.

Излишне придирчивое отношение к непривычным китайским традициям способствует накоплению негативных эмоций, таких как депрессия, разочарование, раздражительность и так далее. Стремление закрыться от освоения непривычного культурного опыта затруднит их межкультурную адаптацию к китайской культурно-бытовой среде и затруднит межкультурное общение с китайскими коллегами.

Выйти из затруднения поможет стратегия постепенного привыкания иностранных экспертов к иному культурному пространству, восприятие новой культуры посредством неформальных контактов с киайскими коллегами и друзьями. 
Поэтому целесообразно ограничение чрезмерных контактов иностранных специалистов на ранней стадии их работы в Китае с иностранными группами. В этот период иностранным специалистам целесообразно активнее взаимодействовать с местным населением и использовать перекрёстные контакты для культурной адаптации.

\section{3. Непрерывное изучение языка и культуры.}

В настоящее время только несколько университетов предлагают курсы китайского языка для иностранных экспертов. При этом большинство иностранных специалистов не могут посещать курсы из-за дефицита времени. Поэтому целесообразно, чтобы иностранные эксперты после приёма на работу в китайские университеты самостоятельно изучали китайский язык для преодоления языковых барьеров в повседневной жизни.

Более важным, чем изучение языка, является изучение китайской культуры, повседневных привычек и образа жизни китайского общества. Этому помогает чтение книг по китайской истории и культуре, активное общение с большим количеством китайских коллег и друзей, знакомство с китайской культурой в их семьях. Это способствует пониманию разных культур, улучшает межкультурную адаптивность экспертов.

\section{Использ уеная литер ат ир а:}

1. Редфилд Р., Линтон Р., Херсковица М. Меморандум по изучению культуризации. Американский антрополог.1936. № 38. С. 149-152.

2. Иммигрантская молодежь: Аккультурация. Идентичность и адаптация / Дж. Вуберри, Дж. Сфинни, Д. Ласам, П. Ведер. Прикладная психология. 2016. № 55 (3). С. 303-332.

3. Менденхал, М. Одду Г. Размеры экспериментальной аккультурации. Академия управленческого обзора. 1985. № 10 (1). C. 39-47.

4. WARD C. \& KENNEDY A. Locus of Control, Mood Disturb - ance and Social Difficulty during Cross-Cultural Transitions [J]. International Journal of Intercultural Relations, 1992, 16 (3). $175-194$.

5. Исследование и предложения по текущей ситуации культурной адаптации иностранных студентов в Китае / Сунь Лецинь, Фэн Цзянпин, Лин Ли и др. Преподавание и исследование языкков. 2009. № 1. С. 41-48.

6. Обзор исследований по влияющим факторам межкультурной адаптации / Чэнь Хуэй, Че Хуншен. Прогресс в области психологических наук. 2003. № 11 (6). С. 704-710.

7. Дуань Л. Предварительное исследование по межкультурной адаптации иностранных преподавателей в китайских университетах. Ханчжоу: Ханчжоуский педагогический университет, 2011. 115 с.

\section{References:}

[1] Redfild R., Linton R., Herskovica M. Memorandum po izucheniyu kulturizacii. Amerikanskij antropolog.1936. № 38. S. 149-152.

[2] Immigrantskaya molodezh: Akkulturaciya. Identichnost i adaptaciya / Dzh. Vuberri, Dzh. Sfinni, D. Lasam, P. Veder. Prikladnaya psihologiya. 2016. № 55 (3). S. 303-332.

[3] Mendenhal, M. Oddu G. Razmery eksperimentalnoj akkulturacii. Akademiya upravlencheskogo obzora. 1985. № 10 (1). S. 39-47.

[4] WARD C. \& KENNEDY A. Locus of Control, Mood Disturb - ance and Social Difficulty during Cross-Cultural Transitions [J]. International Journal of Intercultural Relations , 1992, 16 (3). 175-194.

[5] Issledovanie i predlozheniya po tekushej situacii kulturnoj adaptacii inostrannyh studentov v Kitae / Sun Lecin, Fen Czyanpin, Lin Li i dr. Prepodavanie i issledovanie yazykov. 2009. № 1. S. 41-48.

[6] Obzor issledovanij po vliyayushim faktoram mezhkulturnoj adaptacii / Chen Huej, Che Hunshen. Progress v oblasti psihologicheskih nauk. 2003. № 11 (6). S. 704-710. 
[7] Duan L. Predvaritelnoe issledovanie po mezhkulturnoj adaptacii inostrannyh prepodavatelej v kitajskih universitetah. Hanchzhou : Hanchzhouskij pedagogicheskij universitet, 2011. 115 s.

ЧЕНЬ ЧЕНЬЛН, СюЙ МЕНГЛН. Адаптація іноземних експертів в КНР.

В статті аналізуються особливості адаптаиії іноземних експертів, які постійно працюють в провіниії Чэсеизян; розкриваються основні напрями адаптаиії, такі як міжособистісна, психологічна, культурна, побутова. Висвітлюються чинники, що впливають на міжккультурну адаптацію експертів $з$ різних країн і пропонуються заходи, які можуть сприяти їх адаптачиї до місчевої культури.

Ключові слова: міжкультурна адаптачія, іноземні експерти, провінція Чжеизян.

CHEN CHENLIN, SyUJ MENGLIN. Adaptation offoreign experts is in peoples Republic of China.

The article analyzes the features of adaptation of foreign experts, constantly working in Zhejiang province; reveals the main directions of adaptation, such as interpersonal, psychological, cultural, household. Factors influencing intercultural adaptation of experts from different countries are highlighted and activities that can help them adapt to local culture are proposed.

Keywords: intercultural adaptation, foreign experts, Zhejiang province.

DOI: https://doi.org/10.31392/NZ-npu-144.2019.29

УДК $378.147: 327.9$

Щербина О. О., Кривцова О. Є.

\section{РОЗВИТОК ПРОФЕСІЙНОї ГОТОВНОСТІ \\ МАЙБУТНІХ ВОЄННИХ ДИПЛОМАТІВ ДО ПУБЛІЧНОГО ВИСТУПУ ЯК ПРЕДМЕТ НАУКОВО-ПЕДАГОГІЧНОГО АНАЛІЗУ}

Сьогодні надзвичайно гостро перед фахівиями різних галузей стоїть потреба в реалізаиії публічної складової професії. Комунікачія є основним компонентом будь-яких виробничих прочесів. Навички людини публічно висловлюватися, аргументувати свою позииію, проголошувати промову створюють комунікативні можливості для особистості і для організації презентувати свою роботу. Авторки статті проаналізували сучасні педагогічні підходи до формування вмінь особистості підготувати ефективний публічний виступ, порівняли основні тенденції реалізаиї найбільш ефективних науково обтрунтованих шияххв навчання публічного мовлення. У статті наводяться приклади комплексного підходу до тлумачення сутності такого інтегративного інтелектуального вміння особистості як вміння публічно виступати. Тут містяться приклади аналізу практичної реалізаиії структурування навчального матеріалу, співвідночення теоретичної підготовки та формування практичних навичок публічного мовлення, а також визначено роль самостійної роботи студентів.

Ключові слова: публічний виступ, навчання публічного мовлення, моделювання комунікативних ситуаџій, ділова гра.

Відкритість і доступність інформації у сучасному світі впливає на професійну діяльність таким чином, що представники різних галузей часто постають у ролі спікерів. Оскільки комунікація $€$ запорукою ефективного функціонування як суспільства в цілому, так і окремих суб'єктів зокрема, то підготовка особистості до публічного мовлення як частини професійної діяльності $€$ нагальною потребою. Ефективна комунікація передбачає не лише доведення інформації, але й інтерпретацію, висвітлення головних фрактів, 